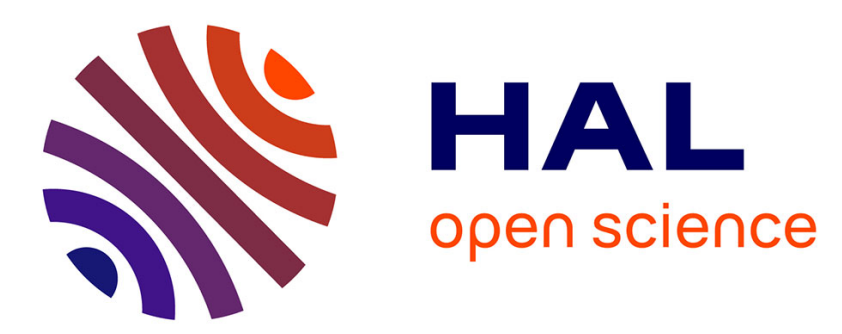

\title{
Efficiency and equity in land conservation: The effects of policy scale
}

Jean-Sauveur Ay, Claude Napoleone

\section{To cite this version:}

Jean-Sauveur Ay, Claude Napoleone. Efficiency and equity in land conservation: The effects of policy scale. Journal of Environmental Management, 2013, 129, pp.190-198. 10.1016/j.jenvman.2013.07.012 . hal-02645069

\section{HAL Id: hal-02645069 \\ https://hal.inrae.fr/hal-02645069}

Submitted on 29 May 2020

HAL is a multi-disciplinary open access archive for the deposit and dissemination of scientific research documents, whether they are published or not. The documents may come from teaching and research institutions in France or abroad, or from public or private research centers.
L'archive ouverte pluridisciplinaire HAL, est destinée au dépôt et à la diffusion de documents scientifiques de niveau recherche, publiés ou non, émanant des établissements d'enseignement et de recherche français ou étrangers, des laboratoires publics ou privés. 


\title{
Efficiency and Equity in Land Conservation: The Effects of Policy Scale
}

\author{
Jean-Sauveur Ay* and Claude Napoléone ${ }^{\dagger}$
}

\begin{abstract}
This paper studies the effects of policy scale for land conservation schemes based on global objectives but implemented at local level. They are explored in the classical reserve site selection framework for policy efficiency, to which we add the common social objective of equity between spatial units. We first analyze the role of the biophysical attributes of land available for conservation. These natural endowments are then combined with different implementation scales to improve a particular land-based social function: natural habitats for biodiversity. An empirical illustration, based on data from the Provence region of France, is used to explore what we identify as a policy scale trade-off between administrative units. This shows the importance of land availability in predicting the distribution of the costs and benefits of conservation schemes. In terms of equity, we find an interior solution that minimizes an inequality metric (the Gini coefficient) along policy scales. Our approach should lead to more socially acceptable conservation objectives, between the usual two extreme cases of autarky and specialization.
\end{abstract}

Keywords: Land conservation ; reserve site selection ; scale trade-off ; equity.

Classification JEL: Q15, Q24, Q25, Q53.

\footnotetext{
${ }^{*}$ Corresponding author. INRA UMR 1041 CESAER, 26 Bd du Docteur Petitjean, F-21000 Dijon (France) jsay@dijon.inra.fr. The authors would like to thank Jean Cavailhès, Romain Julliard, Andrew Plantinga and an anonymous referee for their comments about the present work.

${ }^{\dagger}$ INRA UR 767 Écodéveloppement, Agroparc, F-84914 Avignon cedex 9 (France) claude.napoleone@ avignon.inra.fr.
} 


\section{Introduction}

In most countries, governments regulate land resources via zoning ${ }^{1}$. Land use constraints are imposed in order to obtain an allocation compatible with social demands or to separate those uses that cannot coexist without social costs. Each area is devoted to a principal use: a wildlife reserve or a developable area, for example. Zoning enforcement is relatively easy when it protects an area allocated to a consensual principal function and when the geographical scale is not wide: for example, a natural reserve on a threatened local ecosystem or an urban zone in a town district. However, there is currently pressure to pursue more global objectives (Millennium Ecosystem Assessment, 2005) or to protect "macro-resources" not really within local government's sphere of competence (Costanza and Daly, 1992). One example of these more global objectives is the conservation of biodiversity by preserving natural habitats; another is a low atmospheric concentration of greenhouse gases. This trend obviously presents new kinds of trade-offs between competing land uses, making consensus more difficult (Smith, 2009; Lambin and Meyfroidt, 2011) and posing the question of how to apply international and/or national conservation objectives within local zoning plans. $^{2}$

Here, we simultaneously tackle two of the major determinants of the political acceptance of such zoning plans: efficiency and equity. Efficiency is well covered by the literature, with the tools traditionally used to implement a land conservation scheme within the reserve site selection framework (Polasky et al., 2001; Fischer and Church, 2003; Costello and Polasky, 2004). Typically, such approaches consist in finding the optimal solution to the conservation problem, that is, the best land units to target in accordance with an exogenous objective function and exogenous constraints on natural endowments or on institutional operations. Objectives were usually specified in terms of number of threat-

\footnotetext{
${ }^{1}$ For conservation purposes, see: www . protectedplanet. net or www . wdpa . org.

2 This is not a new economic question (see Peltzman and Tideman, 1972) but one that, in our opinion, is relatively neglected.
} 
ened or heritage species to conserve at the global scale, but major steps forward consisted in acknowledging the need to account for economic costs (Ando et al., 1998; Naidoo et al., 2006) and to construct political schemes that are locally consistent (Kark et al., 2009).

The typical methodology is to select targeted land plots by (i) ordering available plots from best to worst and (ii) protecting plots in decreasing order until the primary objective - number of threatened of heritage species protected, acreage preserved or budget constraint - is reached. While more subtle method can be found in the literature (accounting for the connectivity of reserve sites, vulnerability, ecological thresholds, etc.), "ordering and selecting" remains fundamental to this approach. From an economic point of view, the index generally used to sort plots of land is the ratio of costs to benefits, where costs are measured in terms of land price or in terms of users' willingness to accept a withdrawal of their activities. Benefits are typically measured in terms of number of threatened of heritage species present, their genetic diversity or a monetized provision of ecosystem services. The best plot to protect, intuitively, is the plot that has the lowest ratio.

An interesting feature of this stylized framework is the effect of the scale of decisionmaking, and this applies even to the more refined methods. As the implementation of conservation is always constrained by a set of possibilities depending on natural endowments - the quantity and quality of land - it is easy to show that selection cannot be more effective for any spatial subset of the initial set of possibilities. Reducing the available plots for an optimized plan always increases the weight of the land availability constraint and thus, mechanically, the final cost-benefit ratio. As Kark et al. (2009) explain, when the land base is reduced, some desirable plots are no longer available for conservation, so implementation has to be redirected to less desirable plots. In other words, it is best to extend the trade-off to the widest land base possible. Empirical evidence of this mechanism is provided later in this article (see Table 2 and Figure 3.) 
Equity is a much more implicit attribute of this kind of reserve site selection models for decision making, although it is also an important determinant of the political acceptance of land conservation choices. An underlying redistribution between smaller administrative units is always an underlying outcome of such conservation choices. This political dimension is clearly overlooked in the regulatory decision-making literature (Ludwig et al., 2001) although equity considerations shape spatially any conservation scheme. In particular, we show that equity considerations make program constraints about land availability more restrictive. As an example, the US Farm Act's Regional Equity Provision provides a stylized introduction of equity considerations into a conservation program (Nickerson et al., 2010).

The policy only focused on efficiency therefore focuses on land plots with the best benefit/cost ratios, even if only cover a small part of a given region. Due to well-documented spatial heterogeneity (Newburn et al., 2005; Nelson et al., 2008), this spatial specialization excludes from the conservation effort the less well-endowed parts of the region. Conversely, the equity objective tends to extend conservation costs to cover each local subdivision. This equity-induced spatial homogenization generates a specific additional cost of protecting land plots with lower benefits and higher costs. Nevertheless, this self-sufficiency in conservation, which we term autarky, can be justified by the desire to share costs and benefits equally (see official publications like World Bank, 2006 or the community-based conservation literature Berkes, 2004, 2007).

Within this context, our analysis compares different scales for the implementation of a policy that aims to conserve land to provide a "macro-resource." Section 2 begins with a presentation of the theoretical framework relating to natural resources endowments and equity in conservation implementation, showing the underlying scale trade-off of a zoning policy. In section 3, we present the data used to illustrate the theoretical statements: data on biodiversity and agriculture in the Provence region (France). Then, in section 4, 
we simulate some zoning options aimed at an increase of heritage species habitats. In particular, we study the outcomes of different scale trade-offs by considering different land conservation policy scenarios. Our two principal findings are: (i) for a same aggregate gain, aggregate costs may vary up to $450 \%$ according to the implementation scale; (ii) a simple inequality metric (the Gini coefficient), computed on the costs of conservation efforts, can be used to determine an interior scale trade-off between autarky and specialization. The article concludes with a discussion of potential applications in section 5 .

\section{Methods: Theoretical framework}

An international agreement, such as the Convention on Biological Diversity (Nagoya 2010), aims to protect a "macro-resource" (for example by increasing the number of natural habitats and/or protected species) wherever it's located, in a context of worldwide land use change (Vitousek et al., 1997; DeFries et al., 2007). This means that the quantified macro-goal is generally promoted without any precise description of local implementation. However, for conservation policy to be put into operation, global objectives need to be divided up locally. This change of scale modifies the potential cost of conservation, according to the natural and economic endowments of each subdivision and the local cost of substitution between land uses. We describe here more precisely the theoretical framework that allows us to express this idea in quantitative terms.

\subsection{Intrinsic attributes of land resources}

We assume that the biophysical (or natural) attributes of land are exogenous, that is they are not produced as a result of choices ${ }^{3}$. From a decision-maker's point of view, the set

\footnotetext{
${ }^{3}$ Even if human decisions can affect natural characteristics of land (for example, topography by earthwork or water stagnation by drainage), a land base cannot be seen as bundles of homogeneous units providing a freely-chosen amount of social function. There is no guarantee that the converted units present the
} 
of possibilities for policy enforcement is limited by land resource endowments. Thus, the distribution of land heterogeneity determines the possibility of increasing any land-based social function. But different uses of land do not value heterogeneity in the same way. For example, the suitability of a soil for growing annual crops is not the same as its ability to provide environmental services (Babcock et al., 1997); targeting carbon sequestration is not necessary when targeting species conservation (Nelson et al., 2008). Thus, we assume two types of land heterogeneity: the local agricultural margin per hectare and the number of heritage species. For each land use change from agriculture to conservation, the policy cost is the loss of agricultural margins and the benefit is the number of additional heritage species expected to be observed after a sufficient period. We do not consider the possibility of an increasing economic contribution per unit through intensification.

\subsection{Exogenous demand of macro-resource}

We define the demand in terms of "macro-resource" as exogenous, abstracting the institutional and political processes that express it. Moreover, we assume that it is formulated in terms of heritage species observations. This means that the objective function of the implicit reserve site selection problem is constrained by the number of new heritage species that could be observed by naturalists (given a sufficient period for their re-establishment after the conservation effort). We simulate a conservation policy that envisions changing private use of land in order to obtain more observations of heritage species in the region. Because natural richness is bounded by the stock of species in current natural land uses and because urban land uses are irreversible, it is necessary to allocate some agricultural land to natural use to reach this environmental goal. We assume that conventional agriculture does not produce biodiversity and that conservation policy aims mean changing plot uses from conventional agriculture to a system that protects against anthropogenic

same biophysical attributes and/or the same economic value as in a previous use. 
disturbance, over a long period. So that, nature can re-establish itself. In addition, we assume that, properly managed over a sufficient period, current agricultural areas can achieve the same level of biodiversity as adjacent natural areas. We also assume that land use conversion costs are negligible. The effects of conservation are therefore evaluated by simply comparing the increase in number of heritage species observations (the benefits) to the loss of agricultural margins (the costs).

\subsection{Four rationales for conservation}

As we have seen, the ordering and selection of land plots is a major issue in land conservation enforcement. If the only objective is to minimize costs for given benefits, a good process is to order the land plots by increasing cost/benefit ratio and to begin the selection at the bottom of the vector. Here, this rationale is treated as the first-best. ${ }^{4}$ Nevertheless, the first-best is not always possible in the real world, for example due to a lack of information or ineffective incentive schemes. Because these shortcomings affect results, we consider three other rationales for ordering and selecting land plots, as robustness checks. Thus there are four alternative conservation rationales:

1. The first rationale prescribes a random selection of land between municipalities, i.e., a choice without any consideration of land heterogeneity: neither the costs nor the benefits. As this case is very rarely observed in reality, it should be considered more as a counter-factual benchmark.

2. The second rationale is agriculture oriented and consists in minimizing agricultural costs per unit of land preserved. The regulator sorts the plots by agricultural intensity in increasing order and begins the selection at the bottom, that is, the lowest cost land plots.

\footnotetext{
${ }^{4}$ This result on the optimality of cost/benefit ordering and selection is valid with the classical assumptions retained in our framework. Wu et al. (2001) offer a formal proof in a very similar framework.
} 
3. The third rationale is based on natural intensity: the first land plot to be targeted is the one that presents the highest benefits per hectare.

4. The last rationale uses the cost-benefit ratio and is the first-best previously described. Thus, plots inside the municipality with the lowest ratio of agricultural intensity to natural intensity are targeted first.

\subsection{Implementation scale and equity}

If a conservation policy considers only efficiency, it has to be as global as possible. However, in a politically coherent decision-making context, the equity concern is also an especially important parameter (Brockington, 2003; Banzhaf, 2009). Thus, a government decision cannot apply policy actions and subsidies only to a small part of a given region, even if the best benefit/cost ratio plots are located there. There is a political constraint of equity, of creating a balance between public budgets to avoid depriving any area of the public policy outcome (World Bank, 2006). In this framework, an acceptable implementation scale may avoid depriving any municipality of policy outcomes while minimizing economic costs. But decentralizing the global objective implies additional conservation costs, which may be high enough to hinder social acceptance of the conservation policy. This is the skeleton of the policy scale trade-off, based on the efficiency/equity antagonism, that we illustrate below.

\section{Data: Case study}

The French commitment to the Convention on Biological Diversity takes the form of the "National Biodiversity Strategy" (NBS) 5 . The local implementation plans for NBS,

\footnotetext{
${ }^{5}$ see www.developpement-durable.gouv.fr/IMG/pdf/1_bis___French_National_Biodiversity_ Strategy_-_May_2011.pdf
} 
called "Regional Biodiversity Strategies," contain biodiversity conservation objectives and methods. Issue 13 of NBS provides for equity in biodiversity allocation among municipalities and other local subdivisions. But the additional costs that are acceptable to reach such an equity objective are not discussed. We are clearly in the previous policy scale trade-off, between regional and infra-regional administrative subdivisions. We focus our analysis on one French region (Provence), a Mediterranean region with five million inhabitants. It covers $31,400 \mathrm{~km}^{2}$ and is divided into six intermediate administrative subdivisions or départements: the "Alpes de Haute Provence" (AHP), the "Hautes Alpes" (HA), the "Alpes Maritimes" (AM), the "Bouches du Rhône" (BDR), the "Var" (VAR) and the "Vaucluse" (VAUC). There are 963 municipalities, the smallest administrative subdivision ranging from 58 to 75,968 hectares, with a median area of about 2,395 hectares. An alpine relief marks the boudary of this area in the east, and the Mediterranean coastline marks the southern boundary (see Figure 1).

Figure 1: Land uses and administrative subdivisions of the Provence region (France). Source: OCSOL 2006.

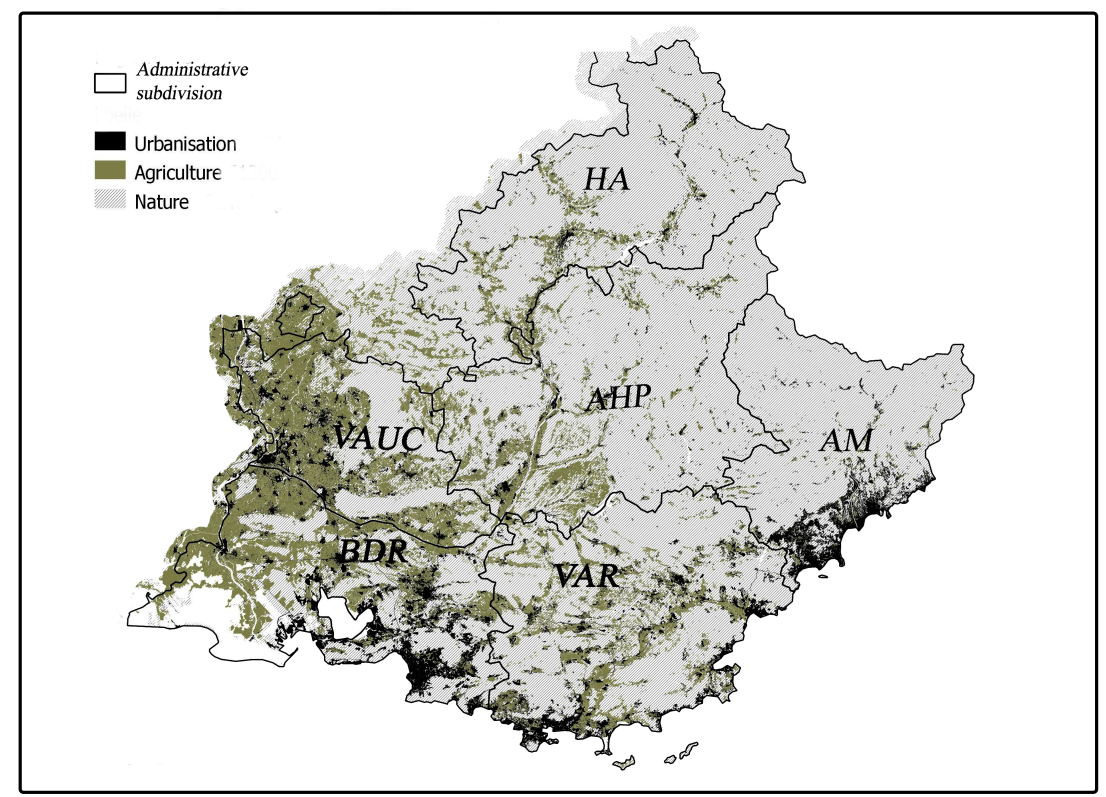

At first glance, from high mountains to Mediterranean coasts, land heterogeneity ap- 
pears to be a major determinant of land use. Using a regional land use pattern at a fine resolution (in 2006), we classified regional land use under three broad categories: agricultural, natural and urban. Conventional agriculture is a relatively important activity in the flat west with its high water availability: it represents $42 \%$ of regional acreage with $21 \%$ for livestock farming and $21 \%$ for crops. In contrast, natural land uses are concentrated in the relief, almost $54 \%$ of the region, and are relatively abundant natural species: the region accommodates about $80 \%$ of French biodiversity, in less than $6 \%$ of the national continental area (Médail and Quézel, 1997). Cities and suburban areas occupy only a modest area, almost $4 \%$, concentrated on the coast. As a consequence of this natural heterogeneity, the six administrative subdivisions are obviously different in terms of land use and potential benefits or costs of providing natural habitats.

We merge these data about land use and administrative subdivisions with a large spatialized census of heritage wild species - fauna and flora - called ZNIEFF (Zones Naturelle d'Intérêt Ecologique Faunistique et Floristique ${ }^{6}$ ). This ZNIEFF database records major ecological sites of the region and catalogue species living in these sites ${ }^{7}$. Each site is a geographical delineation defined as homogeneous in terms of ecological conditions (including land use). There are 828 such zones in the Provence region and their total area extends over $18,274 \mathrm{~km}^{2}$ or around $55 \%$ of the region. We first match this ZNIEFF delineation with the administrative delineation of municipalities, using a Geographical Information System (GIS). The sample excludes some municipalities because of data reliability, leaving a final count of 702 municipalities. Inside this subsample, a total of 742 ZNIEFFs are located, given that a ZNIEFF polygon can be in more than one municipality, and vice versa. The number of heritage wild species per municipality ranges from 0 to 781 , correlated with the number of ZNIEFFs. More precisely, 132 municipalities are represented in

\footnotetext{
6 http://www .paca.ecologie.gouv.fr/-Les-ZNIEFF-de-la-region-PACA.

${ }^{7}$ Several thousand endangered heritage wild species are listed, see: http://www.paca. developpement-durable.gouv.fr/IMG/pdf/ZNIEFF-2eGEN-ANNEXE1-listes_cle2df19d.pdf.
} 
only one ZNIEFF, 621 in less than five, and the maximum is 15 ZNIEFFs (two municipalities). For the agricultural stakes, we use data from the Mutualité Sociale Agricole (MSA). The MSA is the healthcare organization of agricultural trade unions that pays retirement pensions. Each year, it collects information about each farm's economic performance, generating an exhaustive database. This database allows the total agricultural margins for each municipality to be computed in euros as of 2008 .

Using these ecological and economic data, we built an intensity index for the natural and agricultural uses of land at the municipality level. Agricultural margins are used as proxies for agricultural costs of conservation, by dividing the aggregate margins of each municipality by the corresponding agricultural acreage. The number of heritage species observed on each site proxies the intensity providing natural functions with the same division by the corresponding natural acreages. Table 1 summarizes the data. Around the regional average values (right of the table) there are important variations between administrative subdivisions: the max-min ratios are about $110.77 / 9.12=1,146 \%$ for agricultural area, $450.69 / 180.54=250 \%$ for per-hectare agricultural benefits, $394.54 / 136.54=$ $289 \%$ for natural area, and $4.44 / 2.32=191 \%$ for per- $\mathrm{km}^{2}$ number of heritage species.

Municipalities from VAR and VAUC are relatively more agriculture oriented in terms of land use, even through VAR's municipalities contain extensive natural areas. Municipalities from HA and AM contain, on average, fewer agricultural areas and have greater heterogeneity: within these geographical units, some municipalities contain sizable agricultural acreages. In general, there is a high spatial correlation between crop types, biophysical attributes of land, natural and agricultural intensities. Regional livestock farming is extensive and the economic results by unit per acre are low. Thus, AHP and HA, two subdivisions mainly devoted to livestock farming, have relatively low agriculture benefits. The most profitable system is flower production, located in the southeast. There, while AM has relatively limited agricultural areas, it has high agricultural benefits. Our 


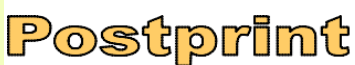

Version définitive du manuscrit publiée dans / Final version of the manuscript published in :

Journal of Environmental Management (2013), Vol. 129, p. 190-198, DOI: 10.1016/j.jenvman.2013.07.012

Journal homepage: http://www.elsevier.com/locate/jenvman

Table 1: Descriptive Statistics for the municipalities of each département.

\begin{tabular}{lccccccc}
\hline \hline & AHP & HA & AM & BDR & VAR & VAUC & TOTAL \\
\hline Agricultural Area & 693.2 & 391.7 & 91.2 & 648.5 & 830.9 & 1107.7 & 644.8 \\
in ha by municipality & $(4.94)$ & $(3.01)$ & $(1.25)$ & $(6.65)$ & $(5.69)$ & $(7.27)$ & $(5.94)$ \\
Agricultural Intensity & 180.54 & 283.95 & 450.69 & 378.68 & 249.53 & 413.56 & 305.90 \\
in euro/ha by municipality & $(228)$ & $(308)$ & $(530)$ & $(489)$ & $(430)$ & $(420)$ & $(400)$ \\
Natural Area & 3945.4 & 3660.1 & 1786.0 & 1416.3 & 3303.7 & 1365.4 & 2734.3 \\
in ha by municipality & $(18.0)$ & $(21.8)$ & $(21.6)$ & $(12.3)$ & $(18.6)$ & $(11.8)$ & $(18.7)$ \\
Natural Intensity & 2.32 & 3.54 & 3.97 & 3.65 & 4.44 & 4.38 & 3.32 \\
in species/ha by municipality & $(0.47)$ & $(0.57)$ & $(1.10)$ & $(0.75)$ & $(1.34)$ & $(0.75)$ & $(1.06)$ \\
\hline Number of Municipalities & 160 & 147 & 81 & 83 & 118 & 113 & 702 \\
Total Agricultural Area & 11,091 & 5,758 & 739 & 5,383 & 9,805 & 12,517 & 45,293 \\
Total Natural Area & 63,126 & 53,802 & 11,421 & 9,185 & 38,984 & 15,429 & 191,947 \\
\hline
\end{tabular}

Notes: Standard deviations are in parenthesis. The difference between the description of the area in the text and the values presented here are due to the 261 municipalities dropped because of data reliability.

sample reports 63,726 heritage species observations in the naturalist catalogue $e^{8}$ on the $19,195 \mathrm{~km}^{2}$ of natural areas: i.e., a mean of 3.32 heritage species observations per $\mathrm{km}^{2}$. The AHP, HA, and VAR administrative subdivisions have relatively more natural areas than BDR and VAUC. Relief seems to be related to quantity of natural areas: AHP, HA and VAR have hills and mountains whereas BDR and VAUC are flatter. However, these distributions change with natural intensity: even where there are fewer natural areas in subdivisions, they present a greater richness of heritage species.

\section{Results: Empirical simulation}

Using our data, the simulation of the four rationales previously described is straightforward. Because information about land heterogeneity is available at the municipality level, we proceed as if all land units inside the same municipality are homogeneous, dividing each municipality land base into 10-hectare plots. Some plots are in agricultural use, oth-

\footnotetext{
${ }^{8}$ A given species observed twice on two different ZNIEFF sites corresponds to two observations.
} 
ers in natural use (recall that land in urban use is excluded). Thus, the region is divided into about 220,000 land plots of known current use and municipality, and therefore of known associated intensity (agricultural cost and natural benefit). We are particularly interested in agricultural land, representing about 40,000 plots. Parts of this land will be used by the conservation policy to increase the number of heritage species.

\subsection{Regional and local objectives}

We restrict our analysis to an objective of 2,400 new observations of heritage species. Implementing the conservation strategies at the regional level consists in ordering all agricultural land plots and selecting the best ones until this primary objective is reached. Figure 2 shows the results presented as three generalized Lorenz curves (Babcock et al., 1997; Ferraro, 2003) for cumulative natural benefits as functions of cumulative agricultural costs. They are computed by summing the two intensities for plots, that are sequentially chosen for conservation. In this figure, if all agricultural land is conserved, the aggregate gain in terms of new species is about 14,000 and the loss in terms of foregone agricultural margins is more than $€ 100$ million. This regional outcome is the same for the four selection rationales because they conclude with the same conservation choice: all agricultural land. However, for a lesser conservation effort, differences appear.

Results for a random selection of land plots are shown in black in Figure 2. In accordance with the law of large numbers with strong independence (applied to the successive conservation choices), the expected cost in random selection is the regional weighted average agricultural intensity and the expected benefit is the regional weighted average natural intensity. For this rationale, the average cost of providing one new heritage species is about $€ 8,500$. For the second rationale (lowest cost first, in blue), land plots are sorted according to their agricultural margins to compute the resulting cumulative costs and 
Figure 2: The four stylized rationales at the regional scale.

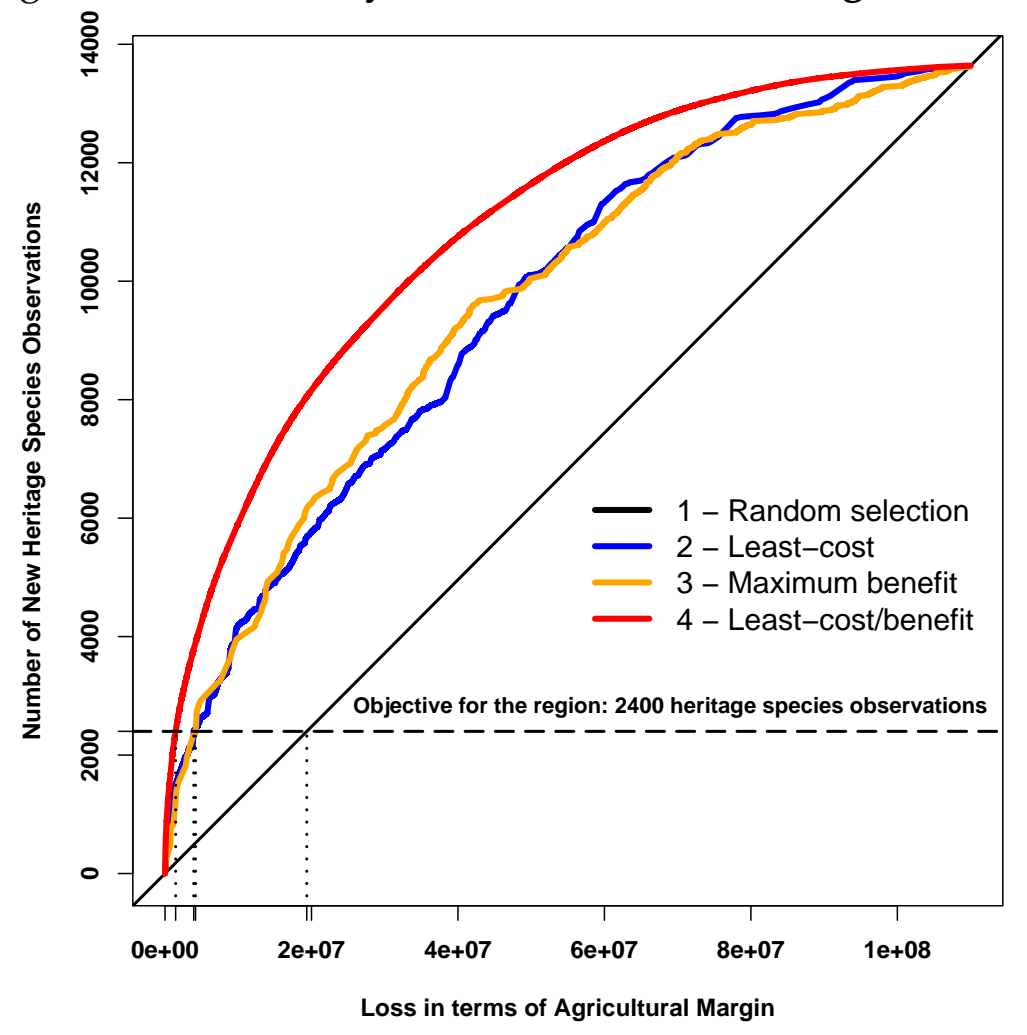

benefits. The third implementation (in orange) corresponds to targeting land plots with the greatest natural intensities, while the fourth (in red) targets those with the lowest cost/benefit ratios. As a result, for any objective in terms of new heritage species observations (from 0 to 14,000 ) cost-benefit selection is less expensive than maximum benefit selection and the lowest-cost selection, which are rather similar. Random selection is always the worst choice: for this regional case, it is always more efficient to have a selection rule based on land heterogeneity. With the particular objective of 2,400 new heritage species observations, the previous general results shown in Figure 2 apply. Depending on the rationale of conservation choices, total agricultural costs equal $€ 19,353,376$; $€$ $3,917,625 ; € 4,164,946$ and $€ 1,449,691$ for the four strategies: the random, the agriculture oriented, the natural use oriented and the first-best, respectively.

When conservation is conducted on such a regional scale, there is no consideration of 
the administrative subdivisions where the policy is implemented. In fact, this situation corresponds to an implicit distribution of conservation costs between the six départements. Thus, for this regional objective of 2,400 species and for each rationale, we can compute the associated threshold values that separate targeted land plots from the others. In the case of least-cost targeting, the conserved plots are such that the agricultural margin is less than $€ 320$ per hectare. For max-benefit targeting, the threshold is formulated in number of new heritage species: only plots with more than, on average, 0.13 species per hectare are preserved. For cost-benefit targeting, the land plots chosen have to present a ratio of agricultural margin to number of heritage species is lower than 1,279 . Because of quantitatively and qualitatively different local land availability, the distribution of the conservation cost is not homogeneous between départements.

Table 2 shows the implicit distribution of such a regional objective when selection is implemented with the fourth (lowest cost/benefit) rationale. The corresponding results for the two other rationales are provided in Table SM1 and SM2 of Supplementary Material (SM). The regional case (at the top of Table 2) illustrates what we previously called specialization. For the regional objective of 2,400 species, more than $80 \%$ of the new heritage species observations are concentrated in two départements (HA and VAR). In contrast to these two major contributors, the other départements each provide less than $7 \%$ of the regional objective, with the extremes of AHP and AM, which provide only around 3\%. Interestingly, conservation costs are just as variable as benefits between départements. More than $80 \%$ of the total costs of conservation are concentrated in HA and VAR. The land plots chosen in this case are, on average, more costly (i.e., present higher per-hectare agricultural margins) in the two départements that contribute most to the regional objective. Even though this result may be different with a different objective, it sheds important light on the unintended consequence of locally deriving a regional objective. The results show some significant differences from the two other rationales presented in SM. Under 


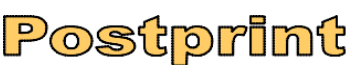

Version définitive du manuscrit publiée dans / Final version of the manuscript published in :

Journal of Environmental Management (2013), Vol. 129, p. 190-198, DOI: 10.1016/j.jenvman.2013.07.012

Journal homepage: http://www.elsevier.com/locate/jenvman

Table 2: The outcomes for the two extremes scales: regional and local.

\begin{tabular}{lccccccc}
\hline \hline \multicolumn{1}{c}{ AHP } & HA & AM & BDR & VAR & VAUC & TOTAL \\
\hline Regional Scale & & & & & & & \\
Benefits & 80 & 227 & 82 & 156 & 1,696 & 159 & 2,400 \\
in species obs. & $(3.33 \%)$ & $(9.44 \%)$ & $(3.40 \%)$ & $(6.49 \%)$ & $(70.72 \%)$ & $(6.62 \%)$ & $(100 \%)$ \\
Area & 2,360 & 3,140 & 1,850 & 3,340 & 12,910 & 3,960 & 27,560 \\
in hectares & $(8.56 \%)$ & $(11.39 \%)$ & $(6.71 \%)$ & $(12.12 \%)$ & $(46.84 \%)$ & $(14.37 \%)$ & $(100 \%)$ \\
Costs & 54,220 & 221,905 & 58,615 & 66,534 & 938,115 & 110,301 & $1,449,691$ \\
in euro & $(3.74 \%)$ & $(15.31 \%)$ & $(4.04 \%)$ & $(4.59 \%)$ & $(64.71 \%)$ & $(7.61 \%)$ & $(100 \%)$ \\
\hline Local Scale & & & & & & & \\
Benefits & 400 & 400 & 400 & 400 & 400 & 400 & 2400 \\
in species obs. & $(16.67 \%)$ & $(16.67 \%)$ & $(16.67 \%)$ & $(16.67 \%)$ & $(16.67 \%)$ & $(16.67 \%)$ & $(100 \%)$ \\
Area & 11,310 & 5,950 & 8,930 & 7,280 & 3,000 & 7,580 & 44,050 \\
in hectares & $(25.68 \%)$ & $(13.51 \%)$ & $(20.27 \%)$ & $(16.53 \%)$ & $(6.81 \%)$ & $(17.21 \%)$ & $(100 \%)$ \\
Costs & 741,841 & 510,517 & $4,249,606$ & 554,185 & 69,041 & 578,747 & $6,703,938$ \\
in euro & $(11.07 \%)$ & $(7.62 \%)$ & $(63.39 \%)$ & $(8.27 \%)$ & $(1.03 \%)$ & $(8.63 \%)$ & $(100 \%)$ \\
\hline
\end{tabular}

Notes: Proportions in parenthesis relatively to regional values.

minimum costs (Table SM1), VAR and AHP are the biggest contributors in terms of both costs and benefits. Under maximum benefits (Table SM2), BDR and VAUC appear to be major contributors, mainly in terms of costs. AHP is no longer a major contributor, though VAR is.

Given such inequalities of conservation costs with the regional implementation, the alternative is to have each département contribute equally to the aggregate objective. ${ }^{9}$ This is what we call "local implementation" of the conservation policy, or autarky. In this case, each département has to provide natural areas sufficient to obtain 400 new observations of natural species, still by converting agricultural land. Intuitively, the costs of this conservation policy differ between départements and between rationales for ordering and selection. For the first-best rationale, the bottom of Table 2 shows the distribution of conservation

\footnotetext{
${ }^{9}$ This remains in accordance with our choice of an exogenous social demand organized at the regional scale. Alternatively, to treat the cost-equity issue more directly, a constant cost of conservation between départements could be imposed. However, because the total cost is simultaneously determined with its spatial distribution, the only means to obtain such a solution is by "trial and error". We consider it beyond the scope of this paper deal with more indirect and less transparent policies of this kind.
} 
costs when the objectives are defined locally, that is, when each département contributes $16.67 \%$. At the right of the table is the loss of efficiency due to the local implementation of conservation objectives: for the same number of new species the aggregate cost is multiplied by more than $6,703,938 / 1,449,691=4.6$.

As a result, the order of conservation burdens is the exact opposite of the order for regional implementation: the administrative subdivisions with the lowest costs in the first case have the highest costs in the second and vice versa. Coupled with the loss of aggregate efficiency, AM accumulates about $63.39 \%$ of the aggregate cost of conservation as opposed to $4.04 \%$ in the regional case. This reversal is also observed in Table SM1 and the Table SM2 for the other rationales. In both cases, AM is the greatest contributor (in terms of costs) in the local implementations. Symmetrically, VAR is the smallest contributor in the local implementations. To synthesize, in the regional implementation scenario, administrative subdivisions with the greatest natural endowments (such as VAR) bear most of the costs of conservation, whereas in the local implementation scenario the subdivisions with lower natural endowments (such as AM) bear most of the costs. The four other départements occupy intermediate positions on this gradient.

\subsection{Equity and the policy scale trade-off}

Potentially, there is an infinite number of local implementations even for a given objective of 2,400 new species observations. Because the political dimension of this social choice is complex, we consider an additional factor in the problem (equity) that allows us to identify the best decentralization scheme and thus resolve the indetermination of the local implementation of conservation policy. To this end, the analysis is restricted to a subset defined between the two previously described extremes: regional and local implementations. This exercise is a heuristic application of the general principle of equity in conservation. Because the objective is to illustrate the variations between scales, 
we define the subset of possible scale trade-offs as a continuum of objectives that admits previous rules as two extreme cases. Mathematically, the simplest means to proceed is to specify a continuum of weights from 0 to 1 , to modulate the objectives of the administrative subdivisions from autarky to specialization. This parameter $P$ is called the weight of efficiency: $P=1$ corresponds to the case of regional implementation, the largest land base for reserve site selection, and $P=0$ corresponds to local implementation, the most constrained. This modulation must be implemented under the constraint of the same quantity of new heritage species observations at the regional scale. By noting $N_{r}$ this global objective (2,400 here), $D$ the set of small administrations (6 départements here, $D \equiv\{A H P, H A, A M, B D R, V A R, V A U C\})$ and $N_{d}^{*}$ the number of observations provided by the administration $d \in D$ in the regional implementation, we have a continuum of local objectives $\left(N_{d}(P)\right)$ as follows:

$$
N_{d}(P)=P \times N_{d}^{*}+(1-P) \times\left(N_{r} /|D|\right)
$$

For each département $(d)$, the number of new heritage species observations required is a function of demand in the regional (first-best) implementation, the demand in the local implementation and the value of $P$. Note that $P$ is the same for all administrative subdivisions, so we can prove that all scale trade-offs for $0 \leqslant P \leqslant 1$ provide the same total quantity of new heritage species observations at the regional scale.

With this subset of scale trade-offs, we simulate the conservation for all the different values of $P$ : from 0 to 1 , step $=0.01$. For each $P$, objectives are split according to (1). Then, cost/benefit ordering and selection is implemented for each département, and cumulative costs are computed. The regional aggregate benefits are constants when $P$ changes and the regional cost of conservation is the sum of the six local costs. This modulation of objectives from $P=0$ to $P=1$ is linear (and strictly dependent on our definition of possible scale trade-offs) but the modulation of conservation costs is decreasing at a decreasing 
rate. As already seen, VAR is constrained to conserve an increasing number of heritage species observations, and the reverse holds for the other administrative units.

From Figure 3, the modulation of the same regional objective corresponds to large variations in threshold cost/benefit values. These shifts imply different average costs of providing more or fewer species in the different administrative subdivisions. The discrete shift from local to regional implementation decreases the total costs of conservation but increases the burden for the relatively better-endowed département: the VAR. When equity is taken into consideration in the conservation objectives, this search for efficiency is not necessarily optimal, and if a region has willingness-to-pay for equity, it might accept a more costly conservation scheme. The equivalents of Figure 3 for the other conservation rationales are also presented in SM: Figures SM1 and SM3. They prove the robustness of our approach to the conservation rationales, because the main structure of the cost and benefits distribution remains unchanged.

We analyze the equity dimension with an inequality measure common in the economic literature: the Gini coefficient ${ }^{10}$. The values of this coefficient are computed for conservation costs between the six départements to determine how inequality evolves with the scale trade-off.

Figure 4 shows, for each $P$, the values of the successive Gini coefficients. The two previous extreme cases in conservation objectives correspond to the highest inequalities in costs, Gini coefficients of about 0.55 . If the départements have exactly the same land endowments, the value of the coefficient is zero. As another extreme case, if all the land plots with the lowest cost-benefit ratios are in the same département, the value of the coefficient is 1 in the regional (specialized) implementation. It is clear that these patterns of inequality are related to local land endowments. The important point here is that there is an interior scale trade-off $(P$ is about 0.62$)$ that minimizes the inequality coefficient on

\footnotetext{
10 The Gini coefficient varies from zero to one; zero is absolute equality and one is absolute inequality.
} 


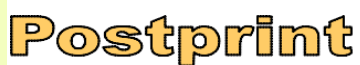

Version définitive du manuscrit publiée dans / Final version of the manuscript published in :

Journal of Environmental Management (2013), Vol. 129, p. 190-198, DOI: 10.1016/j.jenvman.2013.07.012 Journal homepage: http://www.elsevier.com/locate/jenvman

Figure 3: Costs and benefits according to the policy scale trade-off.
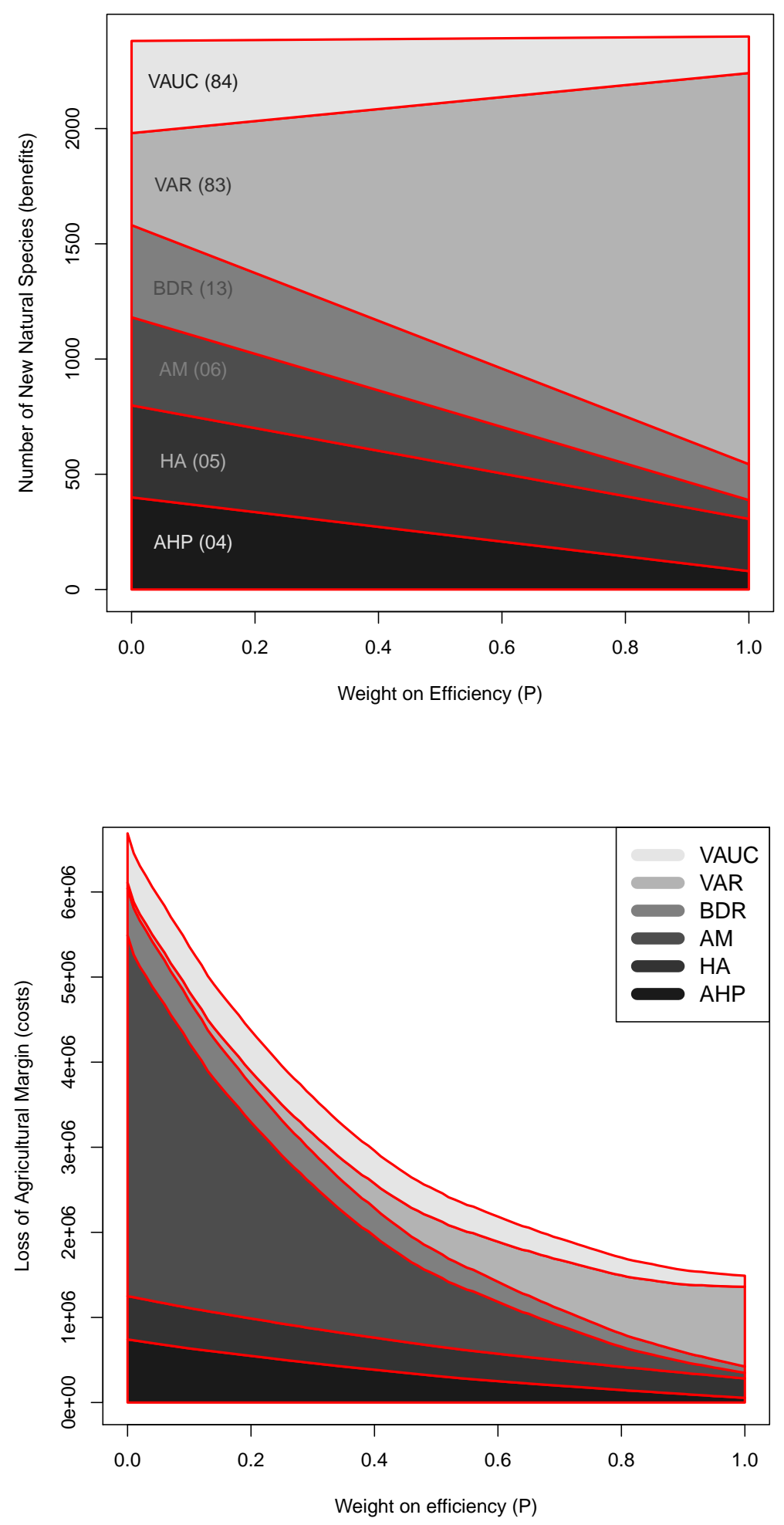
Version définitive du manuscrit publiée dans / Final version of the manuscript published in :

Journal of Environmental Management (2013), Vol. 129, p. 190-198, DOI: 10.1016/j.jenvman.2013.07.012

Journal homepage: http://www.elsevier.com/locate/jenvman

Figure 4: Relationship between Gini index of equity and scale trade-off.

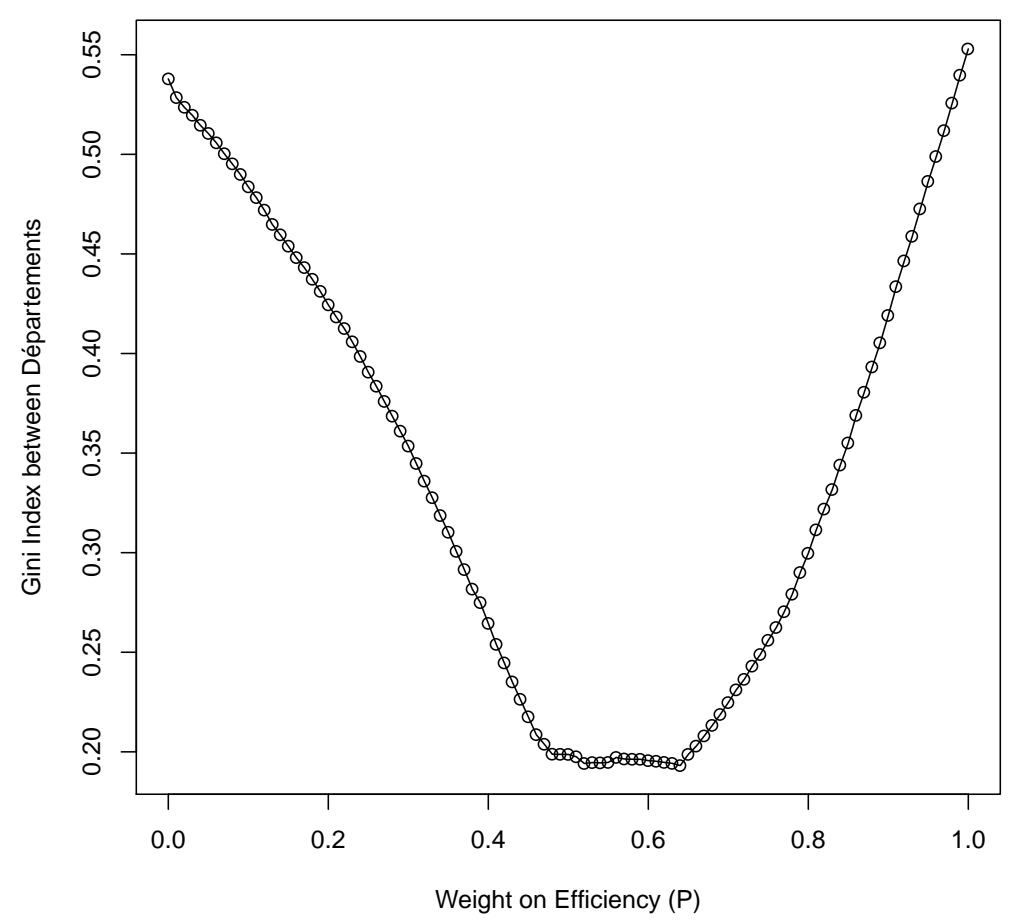


the set of possibilities considered. An interval from 0.5 to 0.6 represents relatively low values for the inequality index, indicating more socially acceptable scales. Other interior solutions are found for the two alternative rationales, lowest-cost and max-benefit, and these results are available in SM: Figures SM2 and SM4. The values of $P$ are not the same but they are close, a little lower for max-benefit selection and a little higher for lowestcost. Even if the scale trade-off associated with minimum equality produces a more costly conservation, implementing the conservation with $P$ of about 0.6 could be more socially acceptable. Acceptance of additional costs will depend on the regional willingness-to-pay for equity which is not the purpose of this paper.

\section{Discussion and conclusion}

The conservation of a "macro-resource" related to land use is an issue for national or more local governments, often implemented on their own budgets. However, the macro nature of the resource implies that the objectives of conservation are exogenous or determined on a larger scale. Such conservation schemes cannot be enforced without defining the land resource base, i.e., land availability, coupled with a policy scale trade-off, i.e., implementation. As a local implementation can generate heterogeneous contributions for different administrative units, political action cannot ignore equity considerations associated with what need to efficient conservation (Nickerson et al., 2010). As a consequence, evaluating the different land plots and determining multi-level additional costs should lead to produce an efficient trade-off when a conservation policy is applied locally. We believe our findings bring insights that will be useful in choosing a local approach like community-based method or participatory action.

This equity cost is studied here in a highly stylized framework to obtain visible results. However, our results may contribute to the debate about how best to distribute 
biodiversity conservation efforts. For example, there is a European Union policy, Natura $2000,{ }^{11}$ that proposes that regions delineate heritage species areas. Certain policies related to Natura 2000 allocate budgets to contracting with farmers or landowners in these areas to protect existing species or to promote policies implementation. Using our approach, the way to manage this policy for an exogenous objective of 2,400 species and to minimize inequality is to set a compulsory objective of 160 species for each département $(0.4 \times(2,400 / 6))$. This provides 960 species $(40 \%$ of the objective) and assure equity in conservation costs. The last 1,440 species ( $60 \%$ of the objective) are conserved in the best endowed départements to assure efficiency in conservation costs.

More theoretically, we show that extending the land base for conservation is a way to decrease costs. There is a monotonic and positive marginal cost trend from total centralization to a totally divisional policy. On the other hand, opportunity cost heterogeneity is a source of inequality between different administrative subdivisions that conflicts with the political objective of equality. Depicting cost variation over the distribution scales is a way to determine an interior trade-off according to the efficiency and equity objectives. It can be a tool for discussing the social value of each land function and for mapping the result of each possible split in order to achieve a better democratic choice.

There are some limitations in our methodology. We do not take into account spatial spillovers, non-linear dynamics, threshold effects and market feedbacks, assuming that these elements change some local valuations but do not affect the overall utility of our methodology. Another limitation concerns the definition and the empirical proxy of natural benefits. We do not allow for the value of species to be heterogeneous (we assume that each species' observation counts for 1), nor for the fact that conserved land can produce other social services ${ }^{12}$ (landscape or water quality for example). Testing stability of

\footnotetext{
${ }^{11}$ See : http://natura2000.eea.europa.eu.

12 These remarks concern the empirical part of our article, but not the theoretical part. It would always be possible to include different values for species (if data are available) and multiples services for the land under conservation (by summing their monetized values). Our theoretical results only require land plots
} 
our results within other (potentially more complex) frameworks should be useful avenue of future research.

As acknowledged in the economic literature on income distribution, the Gini coefficient is more a positive than a normative measure. It is not in accordance with welfare maximization in the particular case of crossing Lorenz curves. While this is not the case here, things may change if our framework is used for other regions. A better inequality measurement has to be related to normative measures that appear in the maximization of an inequality-adverse welfare function (Atkinson, 1970). However, a conservation objective function with a valuation of dis-utility conferred by deviations from equity would be likely to deviate from regional implementation $(P=1)$, as is the usual case in the literature. This result is robust to the use of the Gini coefficient as a metric for equity.

A final perspective open by this work is that of countering the assumed spatial segregation between agriculture and conservation. It is clear, especially in Europe, that agroenvironmental policy is vital to promote natural species conservation. Interestingly, the question of policy scale is shown to be relevant through the use of a particular word in the common agricultural policy: "subsidiarity". Each country can, independently of European budgets, contribute from its own budget to supporting its agricultural sector. To integrate this option into our empirical approach, we would need to introduce more than two uses of land (i.e., differentiate intensive from extensive or organic agriculture), and to know the private opportunity costs of extensive agriculture compared to intensive agriculture and the different extents to which all these different land uses provide habitats for natural species. Once these data become available, it would be useful to confirm that the same pattern of policy scale trade-off emerges, making our findings applicable to the widest range of environmental regulation situation.

to be ordered according to any natural gradient. 
Version définitive du manuscrit publiée dans / Final version of the manuscript published in :

Journal of Environmental Management (2013), Vol. 129, p. 190-198, DOI: 10.1016/j.jenvman.2013.07.012

Journal homepage: http://www.elsevier.com/locate/jenvman

\section{References}

Ando, A., J. Camm, S. Polasky and A. Solow (1998). Species distributions, land values, and efficient conservation. Science 279: 2126-2128.

Atkinson, A. (1970). On the measurement of inequality. Journal of Economic Theory 2: 244-263.

Babcock, B. A., P. Lakshminarayan, J. Wu and D. Zilberman (1997). Targeting tools for the purchase of environmental amenities. Land Economics 73: 325-339.

Banzhaf, H. S. (2009). Objective or multi-objective? Two historically competing visions for benefitcost analysis. Land Economics 85: 3-23.

Berkes, F. (2004). Rethinking community-based conservation. Conservation Biology 18: 621-631.

Berkes, F. (2007). Community-based conservation in a globalized world. Proceedings of the National Academy of Science 104: 15188-15193.

Brockington, D. (2003). Injustice and conservation: Is "local support" necessary for sustainable protected areas? Policy Matters 12: 22-30.

Costanza, R. and H. E. Daly (1992). Natural capital and sustainable development. Conservation Biology 6: 37-46.

Costello, C. and S. Polasky (2004). Dynamic reserve site selection. Resource and Energy Economics 26: $157-174$.

DeFries, R. S., J. A. Foley and G. P. Asner (2007). Land-use choices : Balancing human needs and ecosystem function. Frontier in Ecology and Environment 2: 249-257.

Ferraro, P. J. (2003). Assigning priority to environmental policy interventions in a heterogeneous world. Journal of Policy Analysis and Management 22: 27-43.

Fischer, D. T. and R. L. Church (2003). Clustering and compactness in reserve site selection: An extension of the biodiversity management area selection model. Forest Science 49: 555-565.

Kark, S., N. Levin, H. S. Grantham and H. Possingham (2009). Between-country collaboration and consideration of costs increase conservation planning efficiency in the mediterranean basin. Proceedings of the National Academy of Science 106: 15360-15365.

Lambin, E. F. and P. Meyfroidt (2011). Global land use change, economic globalization, and the looming land scarcity. Proceedings of the National Academy of Science 108: 3465-3472.

Ludwig, D., M. Mangel, and B. Haddad (2001). Ecology, conservation and public policy. Annual Review of Ecological Systematics 32: 481-517.

Médail, F. and P. Quézel (1997). Biodiversity hotspots in the Mediterranean Bassin: Setting global conservation priorities. Conservation Biology 13: 1510-1513.

Millennium Ecosystem Assessment (2005). Ecosystems and human well-being: Biodiversity synthesis. Tech. rep., World Resources Institute, Washington, DC, USA.

Naidoo, R., A. Balmford, P. J. Ferraro, S. Polasky, T. H. Ricketts and M. Rouget (2006). Integrating economic costs into conservation planning. TRENDS in Ecology and Evolution 21: 681-687.

Nelson, E., S. Polasky, D. J. Lewis, A. J. Plantinga, E. Lonsdorf, D. White, D. Bael and J. J. Lawler (2008). Efficiency of incentives to jointly increase carbon sequestration and species conservation on a landscape. Proceedings of the National Academy of Science 105: 9471-9476. 
Newburn, D., S. Reed, P. Berck and A. Merenlender (2005). Economics and land-use change in prioritizing private land conservation. Conservation Biology 19: 1411-1420.

Nickerson, C., M. Ribaudo and N. Higgins (2010). The Farm Act's regional equity provision : Impacts on conservation program outcomes. Tech. Rep. ERR-98, U.S. Dept. of Agriculture, Econ. Res. Serv.

Peltzman, S. and T. N. Tideman (1972). Local versus national pollution control: A note. American Economic Review 62: 959-963.

Polasky, S., J. D. Camm and B. Garber-Yonts (2001). Selecting biological reserves cost-effectively: An application to terrestrial vertebrate conservation Oregon. Land Economics 77: 68-78.

Smith, P. E. (2009). How economic growth becomes a cost: The scarcity multiplier. Ecological Economics 68: 710-718.

Vitousek, P. M., H. A. Mooney, J. Lubchenco and J. M. Melillo (1997). Human domination of earth's ecosystems. Science 277: 494-499.

World Bank (2006). World Development Report: Equity and Development. Tech. rep., World Bank, Washington DC.

Wu, J., D. Zilberman and B. A. Babcock (2001). Environmental and distributional impacts of conservation targeting strategies. Journal of Environmental Economics and Mangement 41: 333-350. 